\title{
A mechanism for cell cycle regulation of sporulation initiation in Bacillus subtilis
}

\author{
Jan-Willem Veening, Heath Murray, and Jeff Errington ${ }^{1}$ \\ Centre for Bacterial Cell Biology, Institute for Cell and Molecular Biosciences, Newcastle University, Newcastle Upon \\ Tyne NE2 4HH, United Kingdom
}

\begin{abstract}
Coordination of DNA replication with cellular development is a crucial problem in most living organisms. Bacillus subtilis cells switch from vegetative growth to sporulation when starved. Sporulation normally occurs in cells that have stopped replicating DNA and have two completed chromosomes: one destined for the prespore and the other for the mother cell. It has long been recognized that there is a sensitive period in the cell cycle during which the initiation of spore development can be triggered, presumably to allow for the generation of exactly two complete chromosomes. However, the mechanism responsible for this has remained unclear. Here we show that the sda gene, previously identified as a checkpoint factor preventing sporulation in response to DNA damage, exerts cell cycle control over the initiation of sporulation. Expression of $s d a$ occurs in a pulsatile manner, with a burst of expression each cell cycle at the onset of DNA replication. Up-regulation of the intrinsically unstable Sda protein, which is dependent on the active form of the DNA replication initiator protein, DnaA, transiently inhibits the initiation of sporulation. This regulation avoids the generation of spore formers with replicating chromosomes, which would result in diploid or polyploid spores that we show have reduced viability.
\end{abstract}

[Keywords: Genetic timer; Sda; SpoOA; replication; DnaA; oscillations]

Supplemental material is available at http://www.genesdev.org.

Received February 26, 2009; revised version accepted June 26, 2009.

Coordination of DNA replication with cellular development is crucial both for prokaryotes and eukaryotes (Shapiro and Losick 2000; Walworth 2000; Murray 2004). A well-studied model for cellular development and differentiation in bacteria is Bacillus subtilis. In response to limiting nutrient sources and cell density signals, $B$. subtilis can differentiate and form a highly resistant endospore within one end of the rod-shaped cell (Hilbert and Piggot 2004). Initiation of spore development is governed by the master regulator SpoOA, which is activated by phosphorylation via a multicomponent phosphorelay including the primary kinase KinA and two intermediate phosphotransferases (Burbulys et al. 1991). Upon phosphorylation, SpoOA P directly acts on more than 100 genes (Molle et al. 2003), setting off a chain of events that takes several hours to complete and culminates in the release of the mature spore from its mother cell compartment.

It has been known for several decades that the initiation of sporulation is intimately linked to cell cycle progression (Dawes et al. 1971), and various lines of experimen-

This paper is dedicated to the memory of Joel Mandelstam.

${ }^{1}$ Corresponding author.

E-MAIL jeff.errington@ncl.ac.uk; FAX 44-191-222-7424.

Article is online at http://www.genesdev.org/cgi/doi/10.1101/gad.528209. tation have shown that there is a window in the cell cycle during which initiation can occur (Mandelstam and Higgs 1974; Dunn et al. 1978; Hauser and Errington 1995). Once cells pass this sensitive point, they must traverse another cell cycle before they are able to enter the sporulation pathway. Despite many years of study, the mechanism responsible for cell cycle coordination of sporulation has remained unclear.

An important insight into the coupling between DNA replication and the initiation of sporulation came from the identification of a replication stress checkpoint system controlled by the AAA+replication initiator protein DnaA (Burkholder et al. 2001). DnaA specifically binds to several classes of DNA recognition elements located within the single origin of replication (oriC) present on the $B$. subtilis chromosome. The ATP-bound form of DnaA is able to form homo-oligomers that mediate the local unwinding of an AT-rich DNA element at oriC (for review, see Mott and Berger 2007). Open complex formation is followed by the assembly of an initiation complex that loads the replicative helicase and recruitment of the remaining replisome components (Kornberg and Baker 1992).

In addition to acting as the initiator of DNA replication, DnaA is also a global transcription factor (Messer and Weigel 1997). Recently it has been shown that in 
response to perturbations in DNA replication, B. subtilis DnaA affects the regulation of several genes (Goranov et al. 2005; Breier and Grossman 2009). One of the targets of DnaA regulation is the $s d a$ gene encoding the sporulation inhibitor protein Sda (Burkholder et al. 2001). Sda is an unstable protein that binds directly to KinA, thereby inhibiting KinA's autokinase activity, and subsequently resulting in reduced levels of Spo0A $\sim \mathrm{P}$ (Rowland et al. 2004; Whitten et al. 2007; Cunningham and Burkholder 2008). DnaA was shown to act as a positive regulator of sda transcription when DNA replication is perturbed (Burkholder et al. 2001; Breier and Grossman 2009). Thus, the Sda checkpoint prevents cells from initiating sporulation under conditions of replication stress (Burkholder et al. 2001; Ruvolo et al. 2006).

We revisited the previously postulated cell cycle dependence of the initiation of spore formation. We show that the sensitive stage within the cell cycle during which spore development can commence is due to oscillations in the concentration of the master regulator of sporulation, Spo0A P. These oscillations are, in turn, partly driven by periodic expression of the $s d a$ gene in response to normal cell cycle cues dependent on the activity of DnaA protein. The results provide a molecular explanation for the coupling of sporulation initiation to cell cycle progression and underscore the need to coordinate DNA replication with cellular development to achieve maximal spore frequency and fitness.

\section{Results}

Direct evidence that sporulation initiates in cells that have completed ongoing rounds of DNA replication

It has been postulated that the sensitive stage in the $B$. subtilis cell cycle, beyond which the cell is unable to sporulate without an additional cycle, could represent a point at which the starved cell has initiated a new round of DNA replication (Hauser and Errington 1995). To examine the replication status of cells that initiate sporulation, we constructed a strain that harbors a fusion of DnaX to a yellow fluorescent protein (DnaX-YFP) and a fusion of the spoIIA promoter to a red fluorescent protein $\left(P_{\text {spoIIA-m }}\right.$ Cherry). DnaX is the $\tau$ subunit of the DNA replication machinery and connects the leading and lagging strand polymerases. The DnaX-YFP fusion forms foci only when cells are actively replicating, thus providing a good marker for active DNA replication in live cells (Lemon and Grossman 1998, 2000). The spoIIA promoter is directly regulated by $\mathrm{SpoOA} \sim \mathrm{P}$ and serves as a reporter signaling the initiation of sporulation (Veening et al. 2005). Individual cells were grown directly under the microscope on top of a thin layer of agarose in such a way that single cells grew into sporulating microcolonies of a few hundred cells (see the Materials and Methods). Phase-contrast and fluorescence images were acquired at periodic intervals to generate time-lapse movies, which contain information encompassing the complete cell division history of individual cells, their replication status, and the final cell fate decision (see the
Materials and Methods). It was immediately apparent that the majority of cells that initiated sporulation, as judged by the onset of spoIIA expression and by subsequent spore formation, were not engaged in DNA replication, as judged by the absence of a DnaX-YFP focus (Fig. 1A,B; Supplemental Movie S1). The average fluorescence from $P_{\text {spoIIA- }}$ Cherry after $9 \mathrm{~h}$ into microcolony development of cells without a DnaX-YFP focus was $8.3 \pm 0.5$ SEM arbitrary units (AU) compared with $3.7 \pm 0.2$ AU of cells with a DnaX-YFP focus ( $t$-test, $P<0.01$ ) (Supplemental Fig. S1). These results are consistent with the longstanding idea that sporulation can only begin after the completion of DNA replication.

\section{Sda as a candidate for the cell cycle regulator of sporulation}

Sda was an interesting candidate for the putative cell cycle regulator of sporulation initiation (see above). To visualize the initiation of sporulation and transcription of $s d a$ in single cells, we constructed a double-labeled strain that harbored both $P_{s d a}-g f p$ and $P_{\text {spoIIA-mCherry fusions }}$ (Supplemental Fig. S2). Time-lapse microscopy showed that there was a reciprocal relationship between the expression of sda and spoIIA (Fig. 1C; Supplemental Movie S2). In particular, the first cells to initiate sporulation, $\sim 9 \mathrm{~h}$ into microcolony development, showed significantly lower levels of sda transcription than other cells $(0.24 \pm 0.01$ vs. $0.37 \pm 0.01 \mathrm{AU}$; $t$-test, $P<0.05 ;>900$ cells measured from three independent movies). Early spore formers represented $\sim 10 \%$ of cells at that time. Importantly, it was also clear that $s d a$ expression was highly heterogeneous under these microcolony conditions (Supplemental Movie S2; Supplemental Fig. S3), supporting the idea that $S d$ could be playing a role in the regulation of sporulation in unperturbed cells, and not just in response to DNA damage. Interestingly, as cells entered stationary phase, the heterogeneity of $s d a$ transcription increased (Supplemental Fig. S3; see below).

To test whether the fluctuations in $s d a$ expression were correlated with the replication status of cells, we constructed a double-labeled strain in which the sda promoter drives expression of mCherry $\left(\mathrm{P}_{s d a}\right.$-mCherry) and active replication can be followed by the DnaX-YFP reporter. Analysis of time-lapse microscopy movies (Fig. 1D; Supplemental Movie S3) showed that nonreplicating cells had reduced $s d a$ expression levels compared with replicating cells $(0.27 \pm 0.02$ vs. $0.45 \pm 0.01 \mathrm{AU}$; $t$-test, $P<0.01 ;>500$ cells measured from three independent movies). These results identified Sda as a likely factor in coupling the initiation of sporulation to the DNA replication status.

\section{A pulse of sda transcription every replication cycle}

The time-lapse movies described above, using microcolony growth, revealed that there is a great deal of cell-to-cell variation in $s d a$ expression, even during the exponential growth phase, when all cells are engaged in DNA replication (Fig. 1C; Supplemental Movie S2). We wondered whether use of a nutritional shift down approach, which generates a greater synchrony in sporulation initiation 


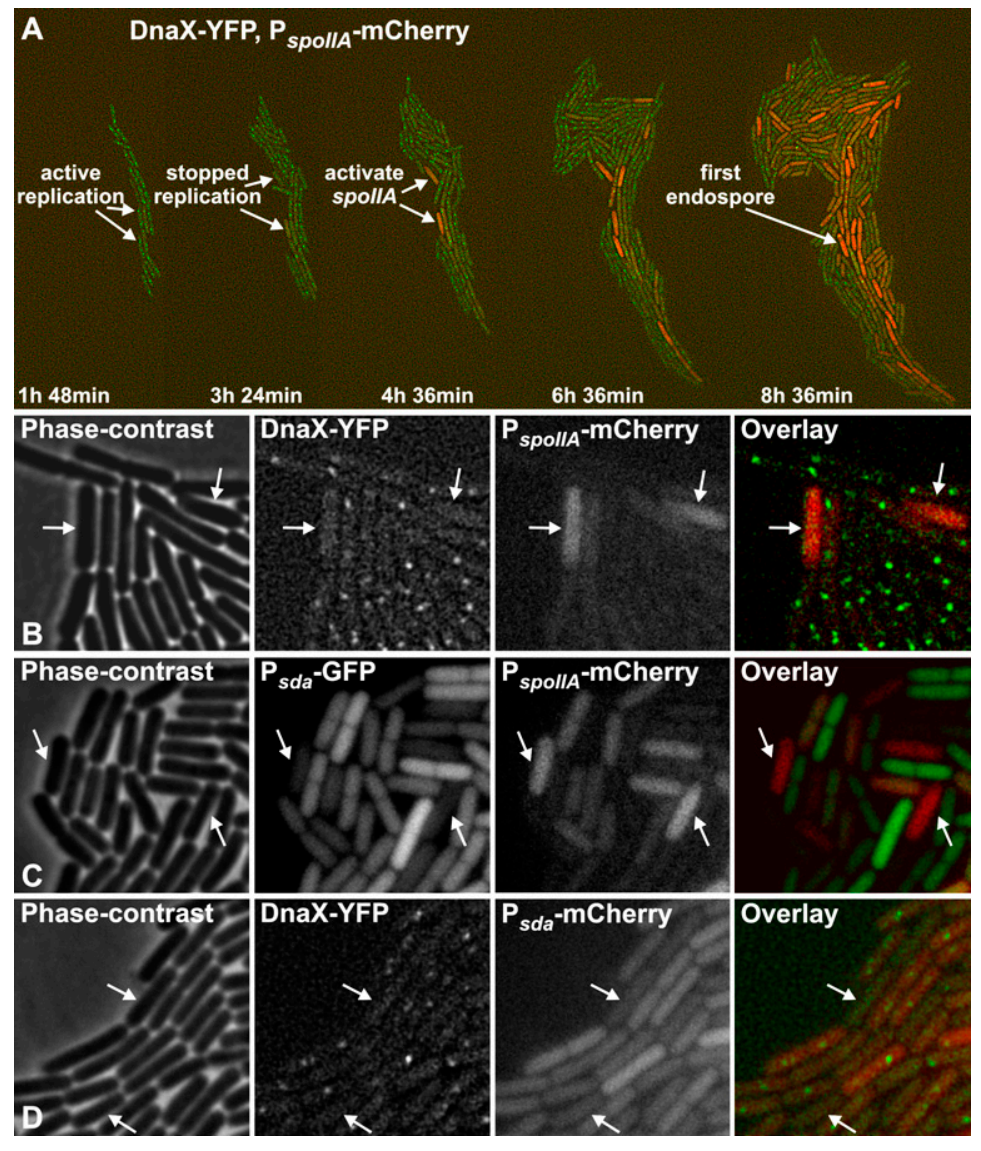

Figure 1. Correlation between replication arrest and the initiation of sporulation. Still frames of time-lapse experiments are shown (also see Supplemental Movies S1, S3). $(A, B)$ Strain JWV017 (dnaX-yfp, $P_{\text {spoIIA-mCherry) }}$ was grown as described in the Materials and Methods. The overlay between DnaX-YFP (green foci) and $P_{\text {spoIIA }}{ }^{-}$ mCherry (red cells) images is shown. Arrows indicate cells that stopped replication early (compared with other cells) and initiated sporulation early. $(C)$ Reciprocal expression between $s d a$ and spoIIA. Micrographs of strain JWV054 (P $\left.P_{\text {sda }}-g f p, P_{\text {spoIIA-mCherry }}\right)$ are shown. Arrows indicate a cell with low $s d a$ transcription levels and high spoIIA transcription levels. (D) Replicating cells show high $s d a$ transcription levels. Micrographs of

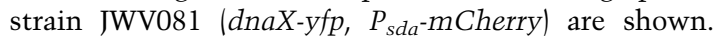
Arrows indicate a cell without a DnaX-YFP focus and low $s d a$ transcription levels.
(Sterlini and Mandelstam 1969), would more clearly report potential fluctuations in $s d a$ transcription. To do this, cells were grown in a rich medium $(\mathrm{CH})$, then resuspended in a nutrient-poor medium (SM) and spotted on SM-based agarose for time-lapse microscopy (see the Materials and Methods for details). We then re-evaluated the behavior of the $s d a$ transcriptional reporter $\left(P_{s d a}-g f p\right)$. Interestingly, under these conditions, the majority of cells exhibited sharp, periodic changes in fluorescence intensity with a period similar to the average cell cycle time. Typically, the pulses showed a relatively rapid increase followed by a slow decrease (Supplemental Movie S4; Supplemental Fig. S4).

To explore whether the transcriptional response of the $s d a$ promoter reflected the expression pattern of the Sda protein, we constructed a $P_{s d a^{-}}$gfp-sda fusion (this GFPSda chimera faithfully reflects in vivo Sda stability) (see Supplemental Fig. S5; Ruvolo et al. 2006). Time-lapse experiments using this GFP-Sda reporter again revealed a striking cyclical pulsing of protein accumulation (Supplemental Movie S5; Supplemental Fig. S6). The pulses of fluorescence generally occurred somewhere between birth and division of the cell, as indicated by formation of a septum, but they were not precisely correlated with these cellular events (Supplemental Fig. S7).

Because transcription of $s d a$ is up-regulated by the replication initiator protein DnaA under conditions of replication perturbation (Burkholder et al. 2001), we wondered whether the pulse of GFP-Sda synthesis might correlate with initiation of DNA replication. To assess cell cycle events under these resuspension conditions, we labeled the oriC region of the chromosome with TetRmCherry, the replisome with DnaX-YFP or GFP-DnaN, and resolved cell shape by membrane staining or phasecontrast microscopy. A typical cell cycle is shown in Supplemental Figure S8. Initially, each replisome was flanked by a pair of replicated origins, and upon replication termination, one of two events occurred-either the cells initiated sporulation or the origins moved back to the quarter positions and a new round of replication started, followed by or simultaneous with symmetrical cell division (Supplemental Fig. S8; Supplemental Movie S6). From these analyses, it became clear that the average cell cycle time increases as the colony develops (for instance, see Supplemental Figs. S6, S9). This is likely due to depletion of nutrients from the agarose slide, which then decreases the rates of DNA replication and cell growth (Wang et al. 2007).

To test the correlation between DNA replication and transcription of $s d a$, we compared $P_{s d a}-g f p$-sda expression with the presence/absence of DnaN-mCherry foci as a reporter for replication. Strikingly, time-lapse microscopy revealed that the start of a GFP-Sda pulse is closely correlated with the first appearance of a DnaNmCherry focus, indicating that the rapid accumulation of GFP-Sda indeed correlates with initiation of replication 
A
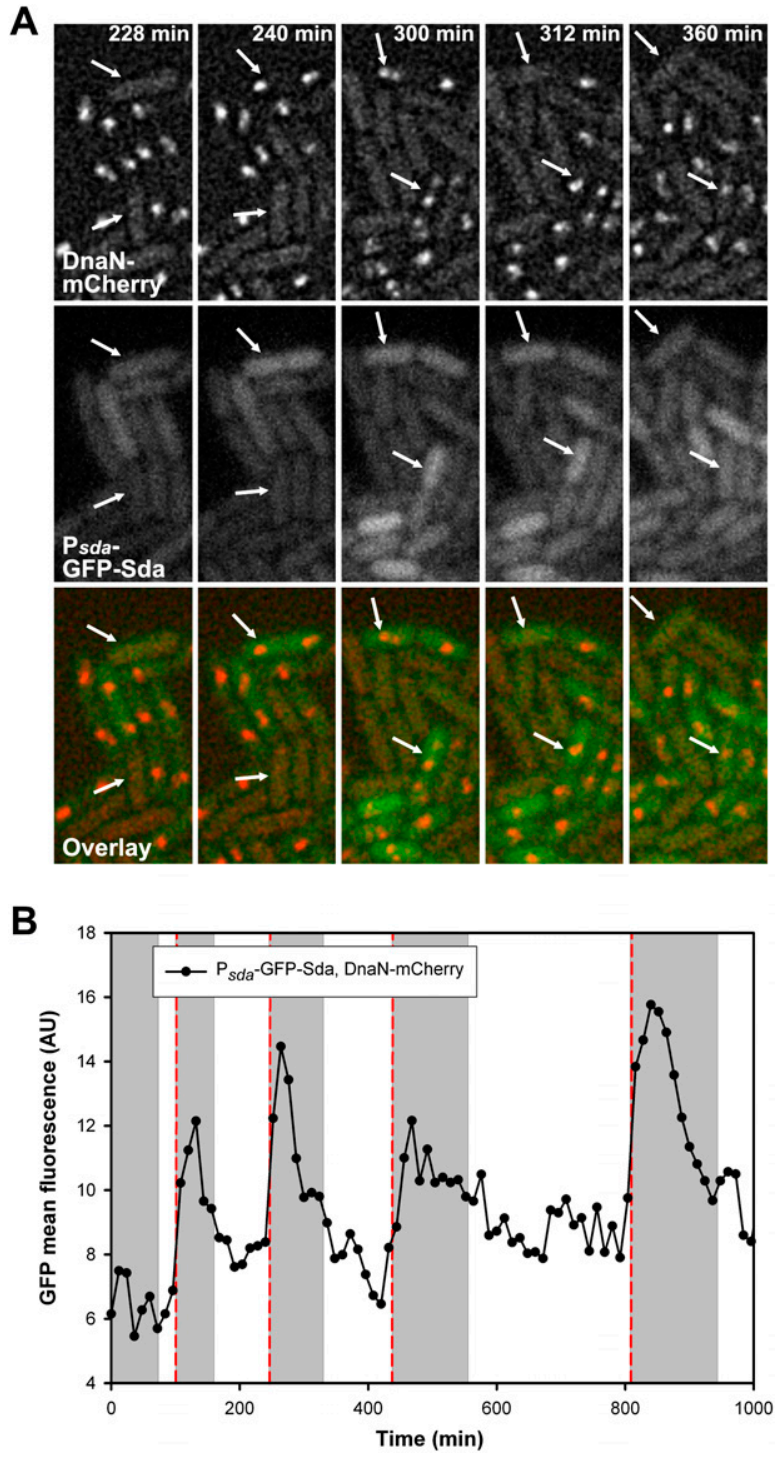

Figure 2. Replication cycle-dependent expression of Sda. $(A)$ Typical still frames from a time-lapse experiment of strain JWV159 ( $P_{s d a}$-gfp-sda, DnaN-mCherry) after nutritional downshift. Arrows indicate a cell that shows a pulse of GFP-Sda fluorescence concurrently with the first appearance of a DnaNmCherry focus (see Supplemental Movie S6). (B) Single-cell trajectory of a typical lineage from strain JWV159. A red dotted line indicates the first appearance of a replisome, and the grayshaded area represents the time a DnaN-mCherry focus is present. After cell division, one of the two resulting siblings is arbitrarily selected for further analysis. The increasing cell cycle length as time progresses is likely due to reduced nutrient availability.

(Fig. 2; Supplemental Fig. S9; Supplemental Movie S7). These results indicate that Sda expression is cell cycleregulated. While cell cycle regulation is ubiquitous in eukaryotes and has been found occasionally in specialized bacteria, such as Caulobacter crescentus (Shapiro and Losick 2000), this is, to our knowledge, the first report of cell cycle-dependent regulation of protein expression in B. subtilis.
SpoOA P levels fluctuate during the cell cycle as a result of $S d a$

Since Sda indirectly inhibits phosphorylation of Spo0A by binding and inhibiting the primary kinases of the phosphorelay (Burkholder et al. 2001), Sda pulsing should be reflected by changes in the levels of SpoOA $\sim$ P. To test this, we examined the expression of GFP driven from the $a b r B$ promoter, which is repressed by low levels of Spo0A P (Perego et al. 1988; Fujita et al. 2005; Veening et al. 2008). The $P_{a b r B}-g f p$ strain was followed by timelapse microscopy after resuspension in SM. As shown in Figure 3A (and Supplemental Fig. S10A; Supplemental Movie S8), the levels of GFP fluorescence driven by the $a b r B$ promoter pulsed during the cell cycle, increasing concomitantly with the initiation of replication.

To compare the timing of $a b r B$ expression with both the initiation of replication and $s d a$ expression, we generated a triple-labeled strain. Time-lapse microscopy of this strain (JWV171) showed that expression of CFP from the $a b r B$ promoter is also tightly correlated with the initiation of replication and that it begins concurrent with or just after the synthesis of GFP-Sda (Fig. 3B; Supplemental Fig. S11; Supplemental Movie S9).

To verify that the observed pulsating transcription of $a b r B$ was the result of oscillations in Spo0A $\sim \mathrm{P}$ levels, time-lapse microscopy was performed on the $P_{a b r B}-g f p$ strain in a $\triangle$ spoOA mutant background. As shown in Figure 3C and Supplemental Figure S10B, mean GFP levels were significantly higher in the $\triangle$ spoOA mutant, and pulses of GFP production were no longer evident. It was also evident that, in the $\triangle$ spoOA mutant, consecutive rounds of DNA replication followed each other more quickly than in wild-type cells (Fig. 3C), indicating that Spo0A directly or indirectly inhibits initiation of DNA replication; for instance, by SirA (see below).

If the $P_{a b r}{ }^{-} g f p$ pulses are indirectly caused by the dynamic expression pattern of $s d a$, then this activity should be abolished in a $\Delta$ sda mutant. Indeed, GFP expressed from the $a b r B$ promoter in a $\Delta s d a$ mutant background failed to pulse and rapidly decreased after resuspension (Fig. 3D; Supplemental Fig. S10C). The $P_{a b r B}-g f p$ pulses were restored by ectopic complementation of sda expressed from its native expression system (Supplemental Fig. S10A). However, the pulses of $a b r B$ transcription were dampened when $s d a$ was transcribed from a constitutive promoter (Supplemental Movie S10).

Taken together, these results indicate that the levels of Spo0A $\sim$ P fluctuate during the cell cycle, likely regulated by the action of Sda. Thus, it appears that DNA replication initiation correlates with expression of Sda and that this signal is propagated into cyclical fluctuations affecting sporulation potential via SpoOA $\sim$ P levels. This mechanism could account for the previously described cell cycle sensitivity of sporulation initiation (see above).

Population-wide studies have shown that SpoOA $\sim$ P accumulates in a gradual fashion over time (Fujita and Losick 2005). Here we find, using a single-cell approach, that SpoOA P increases in an oscillatory fashion during cell cycle progression (Fig. 3B). Concomitant with the 


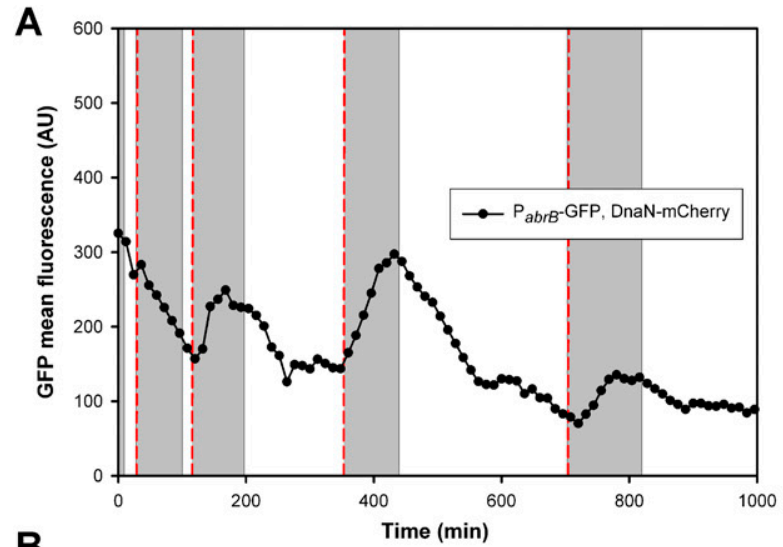

B

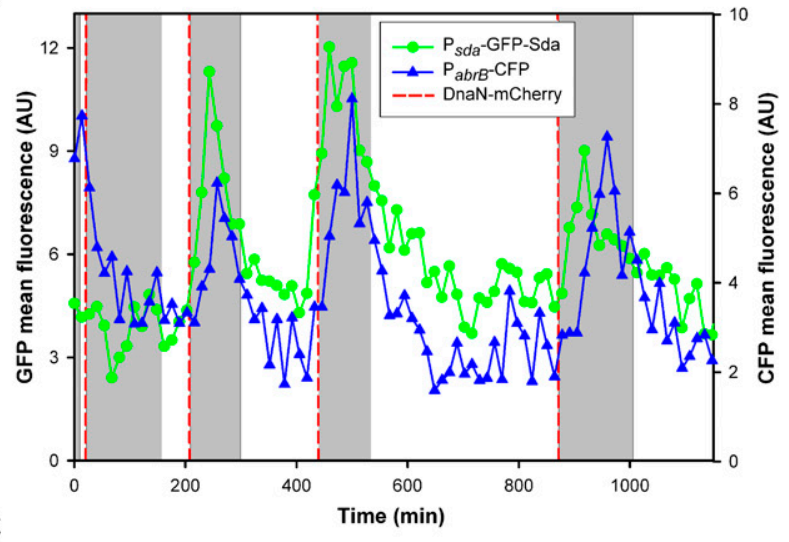

C
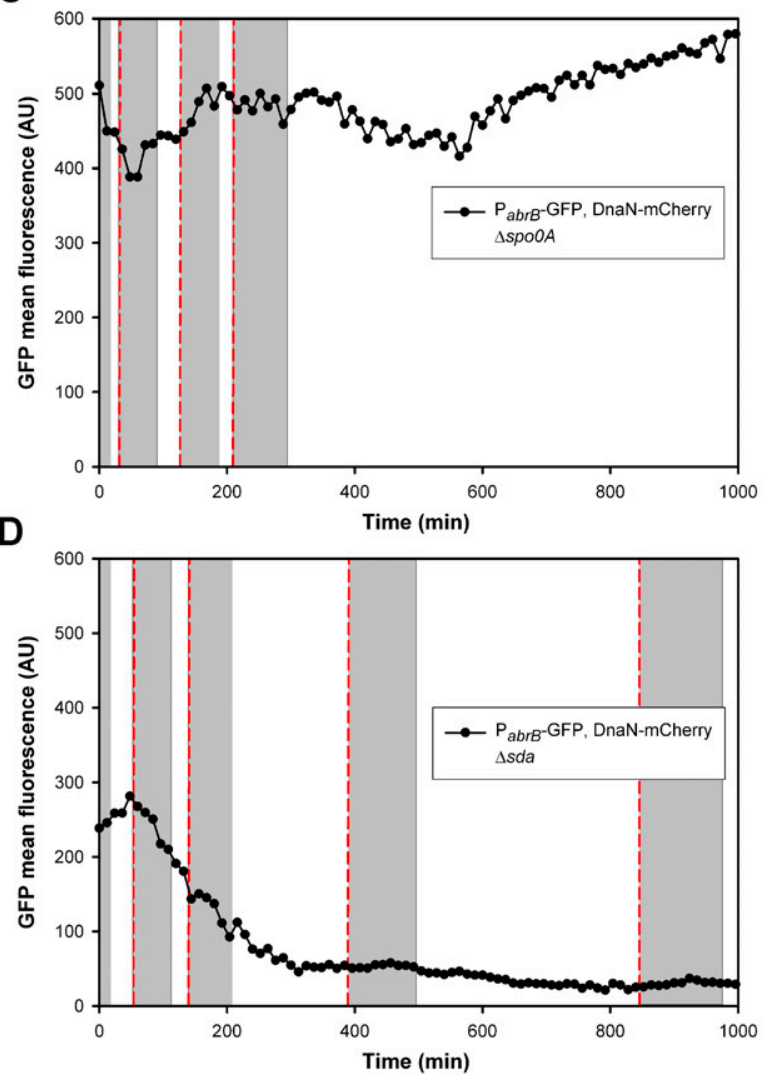

initiation of replication, expression of $s d a$ causes a dip in Spo0A $\sim$ P levels, which in turn causes a pulse of expression of the low-threshold Spo0A $\sim \mathrm{P}$ repressed gene $a b r B$. In this respect, it is interesting to note that expression of rap $A$, encoding a phosphorelay phosphatase under the control of SpoOA $\sim$, shows dynamic expression in a subset of cells (Bischofs et al. 2009). It will be interesting to learn whether a burst of RapA synthesis is important to reduce the levels of SpoOA P at the end of the cell cycle when Sda levels are low and whether it contributes to the oscillatory behavior of SpoOA $\sim$.

\section{Sda is activated by the initiation competent form of DnaA and modulated by LexA and SpoOA}

Sequence analysis of the promoter region of $s d a$ indicated the presence of at least five DnaA boxes (Fig. 4A), and perturbed levels of DnaA are known to affect $s d a$ transcription (Burkholder et al. 2001; Goranov et al. 2005; Ishikawa et al. 2007). Moreover, chromatin immunoprecipitation (ChIP) experiments have shown that DnaA binds to the sda promoter in vivo (Ishikawa et al. 2007) and that levels of DnaA at the sda promoter rapidly increase in response to replication stress (Breier and Grossman 2008). These observations suggest that the replication initiation protein DnaA directly activates transcription of $s d a$. To test this, the expression levels of $P_{s d a^{-}}$ $g f p$ were quantified by flow cytometry in a strain engineered to synthesize different concentrations of DnaA. As shown in Table 1, when cells were depleted for DnaA, sda expression levels were reduced by about twofold compared with nondepleted cells. Although overproduction of wild-type DnaA (strain JVW071) only resulted in a 1.3fold increase of sda expression, overproduction of a mutant form of DnaA (DnaAS326L) that causes overinitiation of replication (Murray and Errington 2008) (strain JWV065), resulted in an $\sim 3.5$-fold up-regulation of $s d a$ (Table 1). This elevated expression does not appear to be caused by a gene dosage effect since expression of $g f p$ from a constitutive promoter (strain JVW205) only slightly increased during DnaAS326L overproduction (Table 1). This result suggests that it is the replication-competent form of DnaA that is responsible for activation of Sda expression.

Sequence analysis of the $s d a$ promoter region also revealed the presence of two consensus Spo0A-binding sites and a binding site for the DNA damage protein LexA (Fig. 4A). While there was a reciprocal correlation between sda and spoIIA transcription (Fig. 1), we noticed that the average fluorescence of cells expressing GFP from the $s d a$ promoter increased as cells entered the

Figure 3. Oscillation of $P_{a b r B}$ expression requires both Spo0A and Sda. Cells were grown and analyzed by time-lapse microscopy as described in Figure 2. Representative traces are shown. $(A-D)$ Single-cell trajectory of strains JWV169 $\left(P_{a b r}-g f p\right.$, DnaNmCherry) (A), JWV171 ( $P_{a b r B^{-}} c f p, \Delta s d a, P_{s d a}-g f p-s d a$, DnaNmCherry) (B), JWV186 (P $P_{a b r B^{-}}$-fp, $\Delta$ spo0A, DnaN-mCherry) $(C)$, and JWV185 ( $P_{a b r B^{-}} g f p, \Delta s d a$, DnaN-mCherry) $(D)$. 

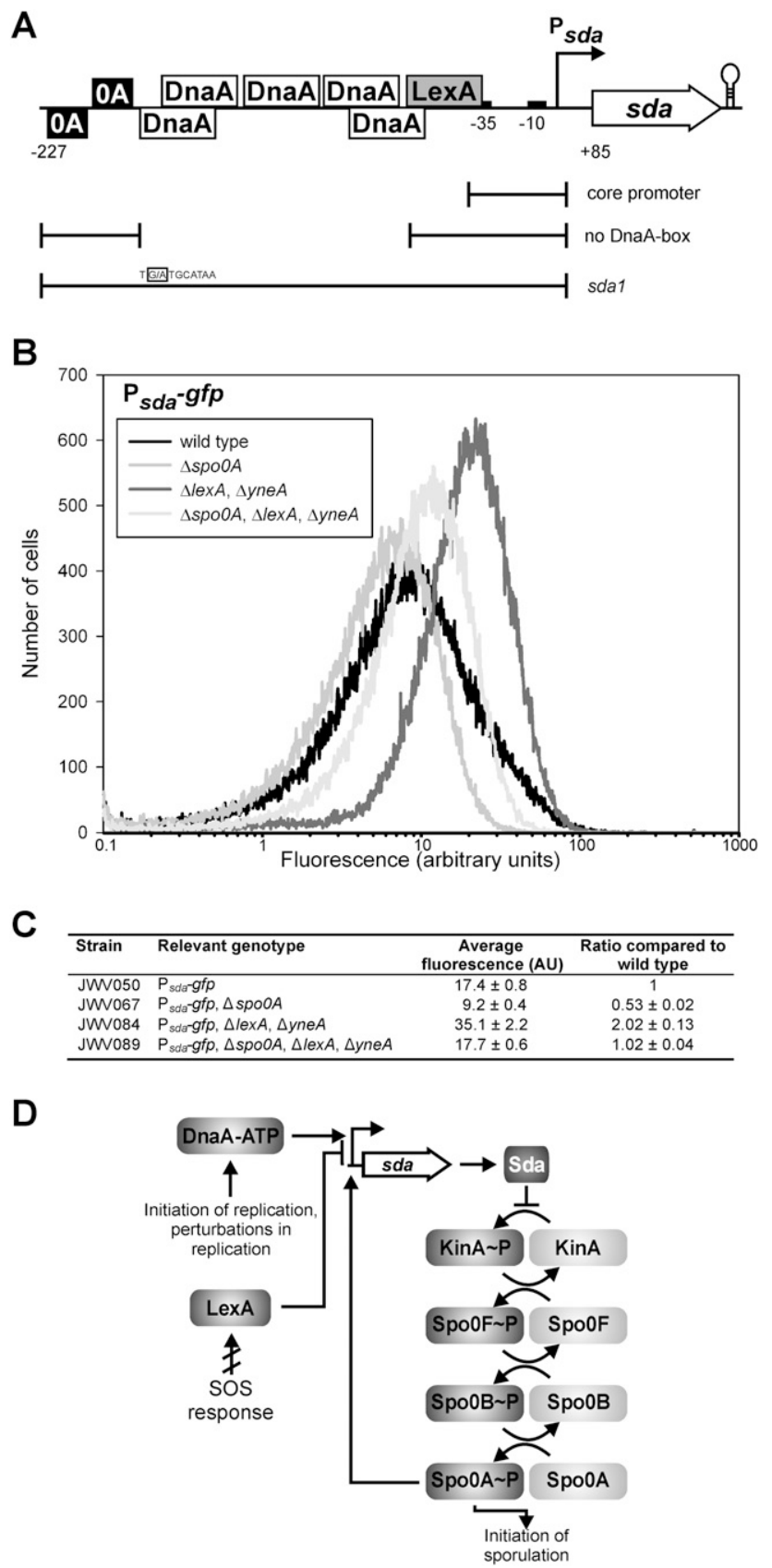

Figure 4. Spo0A and LexA modulate sda transcription. (A) Schematic of the $s d a$ promoter and consensus transcription factor-binding sites. (B) Flow cytometry analysis of strains JWV054 $\left(P_{\text {sda }^{-}} g f p\right)$, JWV067 $\left(P_{\text {sda }}-g f p, \Delta\right.$ spo0A $), J W V 084\left(P_{s d a^{-}}\right.$ gfp, $\Delta l e x A, \Delta y n e A)$, and JWV089 (P sda $^{-}$gfp, $\Delta l e x A, \Delta y n e A$, $\triangle$ spoOA). Cells were grown in minimal medium and collected for flow cytometry at mid-exponential growth. A single flow run is shown for every strain in which at least 100,000 cells were measured. Fluorescence is in arbitrary units. $(C)$ Averaged flow cytometry data from three biological and two technical replicates (six samples per strain). Plus/minus sign ( \pm ) indicates the standard deviation between measurements. $(D)$ Model of the Sda checkpoint network. Arrows and perpendiculars indicate positive or negative activities, respectively. Activation of the SOS response deactivates LexA (slashed lines), thereby relieving LexA-dependent repression of $P_{s d a}$. stationary growth phase (Supplemental Movie S2). Cells expressing GFP from the $s d a$ promoter did not accumulate GFP in the stationary growth phase in a spoOA mutant background, and sda expression levels were approximately twofold lower than those of the wild type during exponential growth (Fig. 4B,C; Supplemental Fig. S12). This is consistent with microarray data suggesting that transcription of $s d a$ is already activated by low levels of Spo0A P (Fujita et al. 2005). Thus, Spo0A P probably acts directly as a positive regulator of sda transcription. While the idea that SpoOA activates $s d a$ expression might seem counterintuitive, it could be important for preventing the Spo0A $\sim \mathrm{P}$ concentration from overshooting and for keeping Spo0A P levels low in cells that have just initiated a new round of replication.

The SOS response in bacteria includes a global transcriptional response to DNA damage mediated by derepression of LexA (Au et al. 2005; Kelley 2006). Previous work has pointed to a role for the SOS response in regulation of sda, although microarray analyses did not detect a significant increase of sda transcription upon induction of DNA damage (Au et al. 2005). DNA-damaged cells of $B$. subtilis are long and filamentous because LexA represses yne $A$, encoding a cell division inhibitor (Kawai et al. 2003). Therefore, we examined expression of

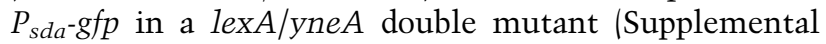
Table S2). As shown in the table in Figure 4C, expression of $P_{s d a}$-gfp was roughly twofold higher in the lexA/yneA mutant background compared with the wild type. The consequence of LexA regulation of sda transcription would be that SOS-stressed cells are inhibited from entering sporulation. Notably, overproduction of DnaAS326L in the absence of the SOS response still led to an increase of sda expression (data not shown). The lexA/yneA double mutant still accumulated GFP during the stationary growth phase, indicating that the positive role of Spo0A $\sim \mathrm{P}$ is not exerted via derepression of LexA. In fact, a lexA/yneA/spoOA triple mutant showed $s d a$ expression levels 0.5 -fold lower than those of a lexA/yneA double mutant (Fig. 4C). Furthermore, under the conditions of microcolony development, sporulation was completely blocked in the lexA/yneA double mutant, and this $\mathrm{Spo}^{-}$ phenotype was bypassed by mutation of sda (data not shown). Taken together, these results show that $s d a$ transcription is activated by the active form of DnaA and independently modulated by both SpoOA P and LexA (Fig. 4D).

\section{Cell cycle regulation of Sda by the replication initiation protein DnaA}

To determine the mechanism responsible for cyclical Sda expression we examined the requirement of each of the transcriptional regulators for this behavior. To limit the number of genetic constructs present in these strains, we judged cell cycle progression by cell division events rather than reporter fusions. Mutant analysis showed that neither Spo0A nor LexA is needed for pulsing of $s d a$ expression (Fig. 5A,B). Interestingly, during overreplication (dnaAS326L mutant background), there was frequently 
Table 1. Transcription from the sda promoter is activated by DnaA

\begin{tabular}{|c|c|c|c|c|c|}
\hline \multirow[b]{2}{*}{ Strain } & \multirow[b]{2}{*}{ Relevant genotype } & \multicolumn{4}{|c|}{ Ratio $P_{\text {sda }}-g f p$ compared with wild type [IPTG] ${ }^{\mathrm{a}}$} \\
\hline & & $0 \mu \mathrm{M}$ & $10 \mu \mathrm{M}$ & $100 \mu \mathrm{M}$ & $1000 \mu \mathrm{M}$ \\
\hline JWV071 & $P_{\text {sda }}-g f p, P_{\text {spac }}-d n a A$ & $0.51 \pm 0.08$ & $0.61 \pm 0.03$ & $1.33 \pm 0.14$ & $0.93 \pm 0.09$ \\
\hline JWV065 & $P_{\text {sda }} g f p, P_{\text {spac }}-d n a A S 326 L$ & $1.02 \pm 0.11$ & $1.39 \pm 0.10$ & $3.52 \pm 0.36$ & $2.63 \pm 0.42$ \\
\hline JWV205 & $P_{\text {sda-core }}-g f p, P_{\text {spac }}-d n a A S 326 L$ & $1.22 \pm 0.09$ & $1.06 \pm 0.23$ & $1.24 \pm 0.22$ & $1.83 \pm 0.29$ \\
\hline
\end{tabular}

${ }^{\mathrm{a} C e l l s}$ were grown for $18 \mathrm{~h}$ in minimal medium with the indicated IPTG concentration and analyzed by flow cytometry (at least $10^{5}$ cells were measured). Mean fluorescence intensity values were measured and normalized to data from strain JWV050 $\left(P_{s d a-} g f p\right)$ grown under identical conditions. Data from JWV205 were normalized to data from strain JWV199 ( $\left.P_{\text {sda-core }}-g f p\right)$. Data are from two biological and two technical replicates (four samples per strain). Values shown as mean of four replicates \pm the standard deviation.

more than one pulse of sda expression between cell division events, again indicating that pulsing of $s d a$ is related to the initiation of DNA replication (Fig. 5C). In a $\triangle d n a A$ mutant strain that initiates DNA replication from an ectopic plasmid origin (oriN), pulses of $s d a$ transcription were no longer observed, and sda transcription was significantly reduced (Supplemental Fig. S13).

To be able to work in a wild-type background but still assess whether DnaA causes pulsing of $s d a$ transcription, we constructed a set of mutant sda promoters driving synthesis of GFP-Sda (Fig. 4A). While looking for mutations that allow sporulation in a temperature-sensitive dnaA mutant background (dnaA1), point mutations within the two most upstream DnaA boxes were identified (Burkholder et al. 2001), indicating that these boxes are critical for DnaA-dependent transcriptional activation of $s d a$. In fact, a single point mutation (sda1) in this region disrupts DnaA-dependent transcriptional activation (Burkholder et al. 2001). In line with this, expression of GFP-Sda driven by the sda1 mutant promoter was significantly reduced. However, the pulsatile expression of GFP-Sda was still evident (Fig. 5D), likely because the other DnaA boxes remained active. When we removed the complete regulatory region upstream of the core $-35 /-10$ promoter, including the Spo0A-, DnaA-, and LexA-binding sites, pulsing was abolished and GFPSda was constitutively synthesized (Fig. 5E; Supplemental Movie S11). Moreover, when the major DnaA boxes were removed but the Spo0A- and LexA-binding sites were preserved, pulsing of GFP-Sda was also abolished (Fig. 5F). Taken together, these data indicate that DnaA causes pulsing of $s d a$ expression, likely via direct transcriptional regulation (Fig. 4D).

Interestingly, transcription of two other DnaA-regulated genes, $y v d C$ and $y w l C$ (Goranov et al. 2005; Ishikawa et al. 2007), also showed dynamic expression (Supplemental Movies S12, S13), in contrast to $g f p$ expression from a constitutive promoter (Supplemental Movie S14; Supplemental Fig. S14). This suggests that many genes within the DnaA-regulon have the potential to show pulsatile expression under these experimental conditions.

For Escherichia coli, the activity of DnaA peaks just before replication initiation, after which it is inactivated via a process called RIDA (regulatory inactivation of DnaA) (for review, see Katayama 2001). In C. crescentus, the steady-state levels of DnaA oscillate in a cell cycledependent manner. Furthermore, C. crescentus DnaA activates the oscillatory expression of two regulators to drive the progression of the Caulobacter cell cycle (Collier et al. 2006). How DnaA activity is cell cycleregulated in B. subtilis is largely unknown. Some clues came from a recent study that showed that DnaA is dynamically localized throughout the $B$. subtilis cell cycle and that after initiation of replication, DnaA is spatially sequestered away from the origin (Soufo et al. 2008). This mechanism could contribute to the pulsatile, DnaA-dependent transcription of $s d a$ observed here.

Sda helps to ensure correct chromosome copy number in sporulating cells under overreplication conditions

Overproduction of the active form of DnaA leads to overreplication and activation of $s d a$ expression (Table 1; Murray and Errington 2008). The same is observed when ParA/Soj, a regulator of DnaA activity, is activated (Murray and Errington 2008; data not shown). Moreover, overproduction of DnaAS326L or activation of ParA/Soj causes a dramatic decrease of sporulation initiation, and this inhibition is relieved by mutation of sda (Table 2; Murray and Errington 2008). This effect does not act through induction of the SOS response, since sda transcription was still induced by DnaAS326L overproduction in a lexA mutant background (data not shown). This again indicates that a major role of Sda is to act as a checkpoint system preventing endospore formation when cells are initiating DNA replication.

Strikingly, microscopic analysis of cells that lack Sda and are programmed to overinitiate replication revealed a range of aberrant sporulation morphologies including cells with bipolar endospores and multiple origins within the mother cell compartment (Figs. 6A-C; Supplemental Fig. S15). Interestingly, the dnaAS326L/Asda mutant frequently produced large forespores that contained more than one origin of the chromosome (spores with one origin, $1.22 \mu \mathrm{m} \pm 0.03 \mu \mathrm{m}$ : spores with two origins, 1.67 $\mu \mathrm{m} \pm 0.06 \mu \mathrm{m}$; $t$-test, $P<0.01$ ) (Supplemental Movie S15). Marker frequency analysis of DNA extracted from purified spores formed under overinitiation conditions (i.e., dnaAS326L/Lsda double mutant) showed a similar origin/terminus ratio compared with spores from the wild type or $\Delta s d a$ single mutant (data not shown), indicating that the spores contain two or more complete chromosomes.

To test whether the polyploid spores were viable, spores of the wild-type strain, the single $\Delta s d a$ mutant, the dnaAS326L mutant (which only formed few spores), and 

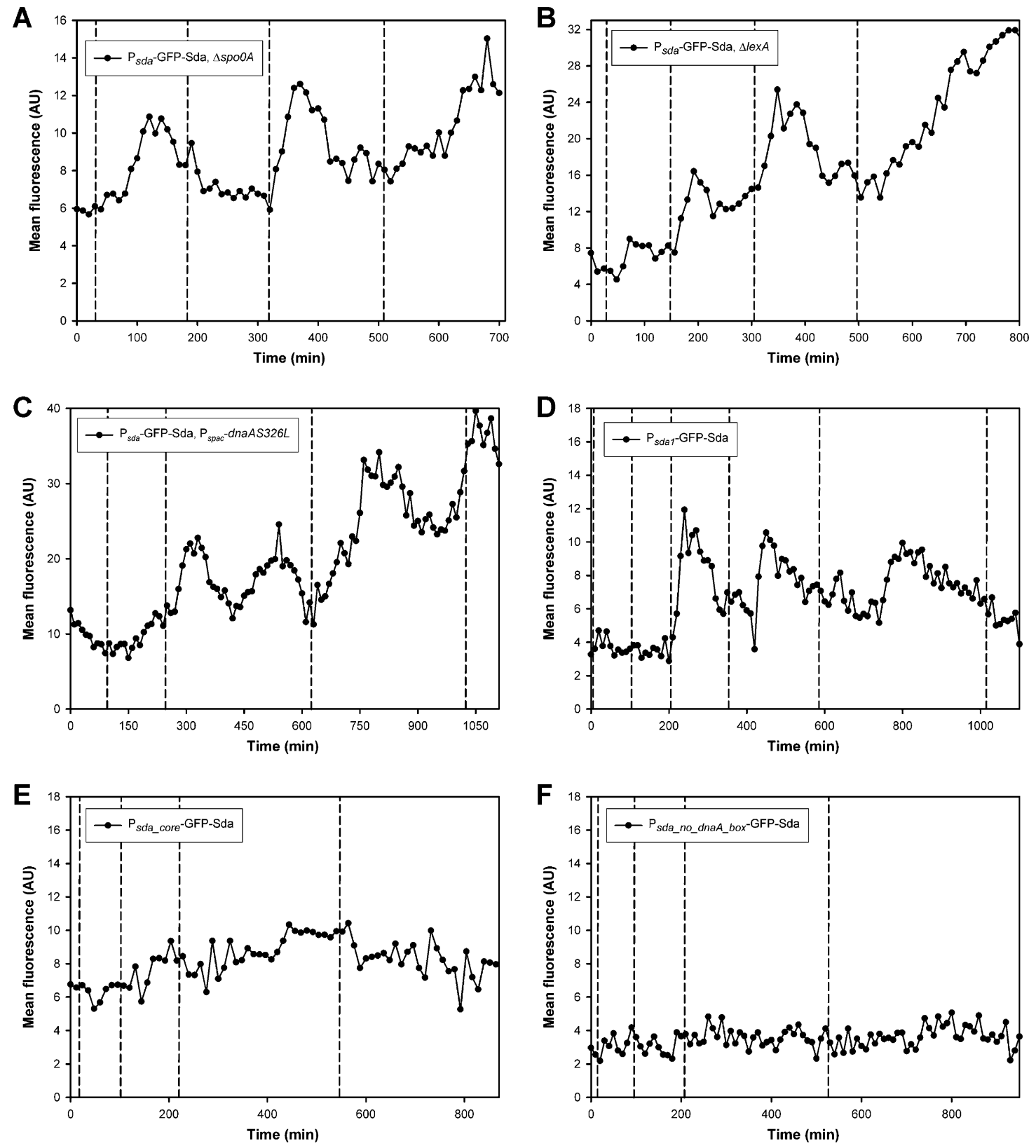

Figure 5. Pulsing of GFP-Sda depends on DnaA. $(A-H)$ Cells were grown and analyzed by time-lapse microscopy after resuspension as described in the main text. Vertical dotted lines indicate a cell division event. Representative trajectories are shown. Single-cell tra-

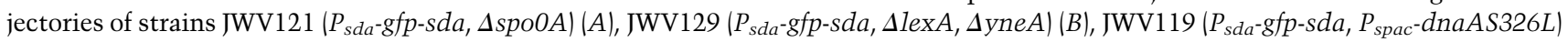
$(C), J W V 153\left(P_{\text {sda }}-g f p\right.$-sda $)(D), J W V 150\left(P_{\text {sda_core }}\right.$ gfp-sda) $(E)$, and JWV151 (P sda_no_dnaA_box $^{-g f p-s d a)}(F)$ are shown.

the dnaAS326L/Asda double mutant were purified. As shown in Table 2, spores that were formed under overinitiation conditions exhibited approximately twofold reduced viability compared with either wild-type or single $\Delta s d a$ mutant spores. This highlights the importance of an efficient block in sporulation initiation by the Sda checkpoint under these conditions.

Transmission electron microscopy showed that spores formed under overinitiation conditions in the $\Delta$ sda mutant are heterogeneous in shape and coat morphology (Supplemental Fig. S16). Comparative time-lapse micros- copy of germinating spores supported the results of the plating assay, with a larger fraction of spores formed under overinitiation conditions remaining phase-bright and failing to germinate (Supplemental Movie S16). Moreover, time-lapse microscopy of germinating spores demonstrated that the spores unable to germinate during the measured period were significantly larger $(1.35 \mu \mathrm{m} \pm$ $0.03 \mu \mathrm{m})$ than successful germinating spores $(1.23 \mu \mathrm{m} \pm$ $0.03 \mu \mathrm{m} ; t$-test, $P<0.05)$.

These results indicate that in the absence of Sda, cells that overreplicate display a polyploid phenotype with 
Table 2. Sda blocks sporulation during overinitiation of DNA replication

\begin{tabular}{llcccc}
\hline Strain $^{\mathrm{a}}$ & \multicolumn{1}{c}{$\begin{array}{c}\text { Relevant } \\
\text { genotype }\end{array}$} & $\begin{array}{c}\text { Total CFU } \\
\mathrm{mL}^{-1}\end{array}$ & $\begin{array}{c}\text { Spores } \\
\mathrm{mL}^{-1}\end{array}$ & $\begin{array}{c}\text { Sporulation } \\
\text { frequency }^{\mathrm{b}}\end{array}$ & $\begin{array}{c}\text { Spore } \\
\text { fitness }^{\mathrm{c}}\end{array}$ \\
\hline JWV054 & Wild type & $4.8 \times 10^{8}$ & $2.1 \times 10^{8}$ & $43 \%$ & 7 \\
JWV074 & $\Delta s d a$ & $7.1 \times 10^{8}$ & $5.6 \times 10^{8}$ & $78 \%$ & 0.98 \\
JWV065 & $P_{\text {spac }}$-dnaAS326L & $3.7 \times 10^{8}$ & $5.6 \times 10^{6}$ & $1.5 \%$ & 0.45 \\
JWV075 & $P_{\text {spac }}$ dnaAS326L, $\Delta$ sda & $3.8 \times 10^{8}$ & $1.1 \times 10^{8}$ & $28 \%$ & 0.55 \\
\hline
\end{tabular}

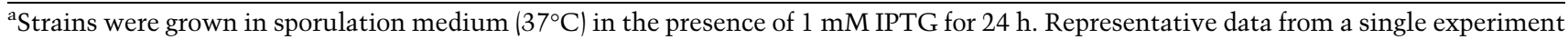
are shown.

${ }^{\mathrm{b}}$ Sporulation frequency as determined by outgrowth of chloroform-resistant spores divided by the untreated total number of cells. The ratio of spores/mL to total CFUs $\mathrm{mL}^{-1}$ is indicated.

${ }^{\mathrm{c}}$ Spores were purified as described in the Materials and Methods, an equal amount of spores was plated, and CFUs were counted for each strain. The fitness value is the normalized CFU ratio compared with the wild-type strain.

mispositioned and excessive origins, resulting in the frequent trapping of two or more chromosomes in the forespore compartment. Importantly, this polyploidy often results in abortive and lethal phenotypes (Figs. 6B,C; Supplemental Fig. S15), demonstrating that Sda plays an important role ensuring correct chromosome copy number in sporulating cells that overinitiate DNA replication.

\section{Sda and SirA coordinate DNA replication} with sporulation

To examine the effects of an sda mutation upon entry into sporulation of cells that are not artificially programmed to overinitiate replication, we performed comparative time-lapse microscopy on strains carrying GFP-DnaN as a marker for replication and $P_{\text {spoIIA-mCherry as a reporter }}$ for entry into sporulation (Supplemental Fig. S17). As shown in Figure 6D, a larger proportion of cells initiated sporulation while still actively replicating in the $\Delta s d a$ mutant background. This indicates that the coordination between DNA replication and sporulation is perturbed in the absence of Sda. Interestingly, however, the sporulation efficiency of an sda mutant is only slightly higher compared with the wild type (Table 2), suggesting that there are additional mechanisms coordinating replication with sporulation in B. subtilis.

In vitro studies indicated that SpoOA $\sim$ P itself might act as an inhibitor of DNA replication by directly binding to the origin region (Castilla-Llorente et al. 2006), but whether this is relevant in vivo remains unclear. Recently, the sirA gene was identified, whose transcription is activated by Spo0A P (Rahn-Lee et al. 2009). It has been proposed that SirA inhibits DNA replication during entry into the sporulation pathway by decreasing the activity of DnaA. Thus, while Sda prevents replicating cells from entering sporulation, SirA would prevent sporulating cells from reinitiating DNA replication. Other than the occasional bipolar endospores formed in either sirA or sda mutants, in our hands these single mutants did not show a strong phenotype compared with the wild type (Supplemental Fig. S18). The sda/sirA double mutant, however, was more severely perturbed in chromosome copy number control and frequently produced bipolar endospores and mother cells containing multiple origins (Figs. 6E; Supplemental Fig. S18). Taken together, the results suggest that both SirA and Sda contribute to proper coordination of DNA replication with sporulation and that they appear to have partly overlapping functions.

\section{Discussion}

Our results demonstrate that during each cell cycle the checkpoint protein Sda couples the initiation of DNA replication with the initiation of sporulation. Sda serves as a genetic timer that allows a window of opportunity toward the end of each replication cycle for Spo0A $\sim \mathrm{P}$ to reach the levels required to initiate sporulation, thus ensuring that a cell enters the sporulation pathway when it contains the correct copy number and has completed DNA replication and repair. Disruption of the coordination of replication and sporulation leads to an increase in the frequency of spores with more than one chromosome and a reduction in spore viability.

In eukaryotes, many checkpoint mechanisms exist to coordinate DNA replication with cell cycle events. For instance, replication checkpoints regulate cyclin-dependent kinases to ensure that mitosis only commences after genome replication is complete (Murray 2004). Importantly, disruption of these cell cycle control mechanisms can result in aberrant cell differentiation. Here we show how the Sda system of $B$. subtilis coordinates DNA replication with cellular development. Intriguingly, both the eukaryotic and bacterial systems detect specific DNA replication initiation events and link this information to a phosphorylation-dependent signaling cascade that drives differentiation. The relative simplicity and tractability of the $B$. subtilis system makes it an excellent model for understanding fundamental aspects of cell cycleregulated coordination of development.

\section{Materials and methods}

\section{Plasmids, bacterial strains, and media}

Plasmids and strains are listed in Supplemental Tables S1 and S2, respectively. Plasmid and strain construction are described in the Supplemental Material. Nutrient agar (Oxoid) was used for routine selection and maintenance of both $B$. subtilis and $E$. coli strains. B. subtilis-specific media were made as described (Harwood and Cutting 1990). For more details, see the Supplemental Material. 


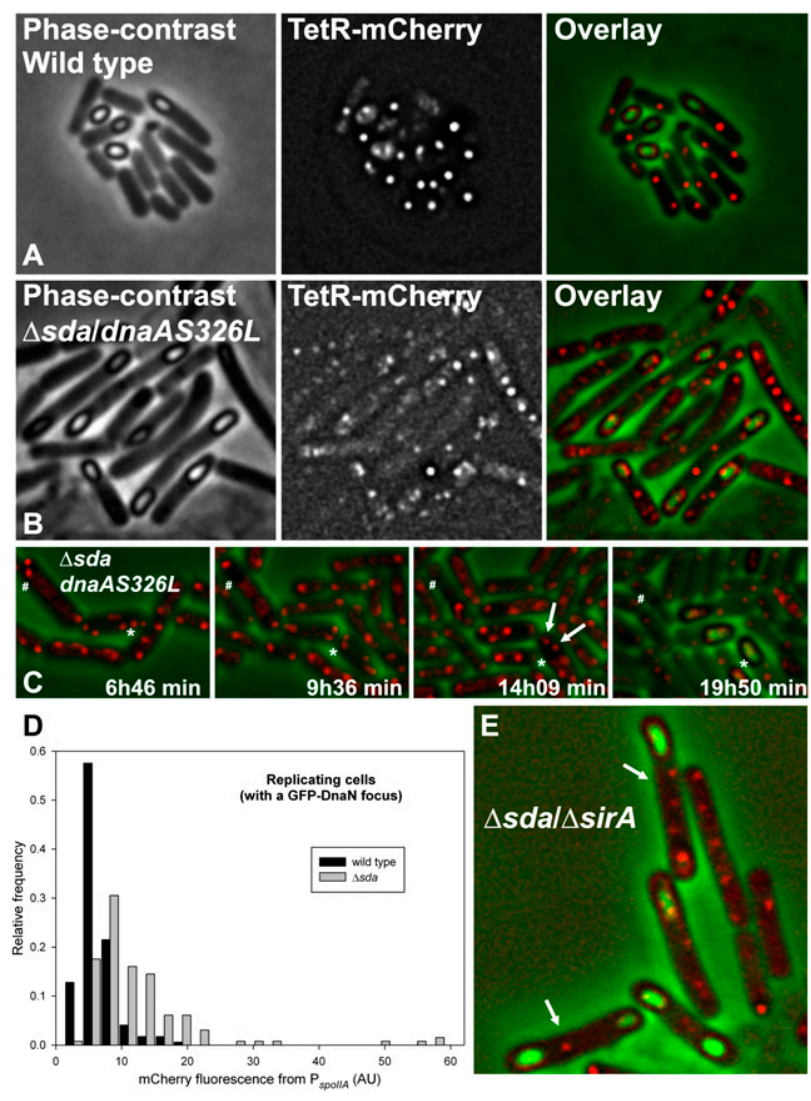

Figure 6. Aberrant sporangial morphologies and perturbed copy number control in the absence of the Sda checkpoint. Wild-type strain JWV086 (hutM::tetO, tetR-mCherry) $(A)$ and strain JWV094 (hutM::tetO, tetR-mCherry, $\Delta$ sda, $P_{\text {spac-dnaAS326L) }}$ $(B)$ were grown for $24 \mathrm{~h}$ in sporulation medium in the presence of $1 \mathrm{mM}$ IPTG and collected for fluorescence microscopy. $(C)$ Time-lapse analysis of strain JWV094 after nutritional downshift (see Supplemental Movie S9). The pound sign (\#) marks a cell committed to sporulate with two origins at one pole and none at the other end, leading to a lethal phenotype. The asterisk $\left({ }^{\star}\right)$ indicates a cell that will form an endospore containing two origin regions. Arrows indicate the two origins. $(D)$ A deletion of sda leads to initiation of sporulation in replicating cells. Still frames of a comparative time-lapse experiment, $5 \mathrm{~h}$ after resuspension, were analyzed for strains JWV201 $\left(P_{\text {spoIIA-mCherry, }}\right.$

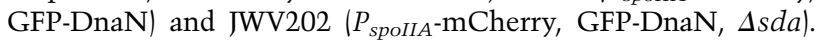
Cells were scored for either the presence or absence of a GFPDnaN focus, and the mean mCherry fluorescence was recorded.

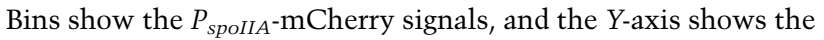
normalized cell count (131 and 172 replicating cells were measured for strains JWV201 and JWV202, respectively). (E) Strain JWV215 (hutM::tetO, tetR-mCherry, $\Delta s d a, \Delta \operatorname{sir} A$ ) was grown for $24 \mathrm{~h}$ in sporulation medium and collected for fluorescence microscopy.

\section{Time-lapse microscopy}

For Figure 1, cells were grown at $30^{\circ} \mathrm{C}$ in Spizizen minimal medium (Spizizen 1958) and inoculated onto a thin, semisolid agarose matrix based on a chemically defined medium and attached to a microscope slide as described (Veening et al. 2008). Nutritional downshift experiments (a.k.a. two-step sporulation assays) were performed at $37^{\circ} \mathrm{C}$ as described (Sterlini and
Mandelstam 1969; Harwood and Cutting 1990). After $10 \mathrm{~min}$, cells were applied to sporulation medium-based agarose and analyzed by time-lapse microscopy (wherein relevant xylose was added [1\%] during this $10 \mathrm{~min}$ to induce expression of TetRmCherry). Germination experiments were performed on LB agarose supplemented with L-alanine $(0.4 \mathrm{mg} / \mathrm{mL})$. Microscope slides were incubated on a temperature-controlled automated Deltavision RT microscope (Applied Precision). Images were obtained up to $24 \mathrm{~h}$ with a CoolSNAP HQ (Princeton Instruments) at $63 \times, 100 \times$, or $160 \times$ magnification. Fluorescent and phase-contrast images were recorded at specified intervals. To prevent phototoxicity, the excitation light (431-441 nm for CFP; 480-500 nm for GFP/YFP; and 541-569 nm for mCherry/FM595) was limited to $32 \%$ of the output of a $100-\mathrm{W}$ Hg-vapor lamp by neutral density filters. Emission wavelengths were 460-500 $\mathrm{nm}$ (CFP), 509-547 nm (GFP/YFP), and 580-653 nm (mCherry/ FM5-95; filters from Chroma). It should be noted that under our experimental conditions for strain JWV171, there was no detectable signal bleed-through from CFP into the GFP channel and vice versa (data not shown). Microscopy images of DnaX-YFP, GFP-DnaN, DnaN-mCherry, and TetR-mCherry were deconvolved using softWoRx (Applied Precision), and figures were prepared for publication using ImageJ (http://rsb.info.nih.gov/ij) and CorelDRAW X3 (Corel Corporation).

\section{Data analysis}

To calculate the difference in sda levels between early spore formers and nonspore formers, still images from three independent time-lapse experiments after $\sim 9 \mathrm{~h}$ into microcolony development were analyzed. The mean fluorescence of both the GFP and mCherry channel was recorded for every individual cell in the three independent still frames and normalized against the highest signal for each still. Background fluorescence per frame was subtracted using a "rolling ball" algorithm (ImageJ), and the normalized $P_{s d a}$-GFP signal from early spore formers $\left(P_{\text {spoII }}{ }^{-}\right.$ mCherry-expressing cells) was compared with the normalized GFP signal of the remaining population. To determine the average $s d a$ expression levels in replicating versus nonreplicating cells, cells were first scored for either the presence or absence of a DnaX-YFP focus. The normalized $P_{s d a}$-mCherry signals were averaged and compared between the two subpopulations as described above.

Single-cell traces were generated by plotting the mean GFP fluorescence intensity (minus background) for an individual cell as a function of time. We determined that manual tracking of the cells was more robust and introduced less noise than automatic cell tracking. Also calculating the mean fluorescence for each cell (by averaging the fluorescence intensity value over every position along a line drawn through a cell) gave less noise than was generated by calculating and/or measuring the total fluorescence for each cell. After a cell division event, one of the two siblings was arbitrarily selected for continuation of the trace. To determine cell division events precisely, we used membrane staining $(0.6 \mu \mathrm{g} / \mathrm{mL}$ FM5-95; Invitrogen) rather than phasecontrast microscopy.

\section{Sporulation assays}

Strains were grown in Schaeffer's sporulation medium (Schaeffer et al. 1965$)$ for $24 \mathrm{~h}$ at $37^{\circ} \mathrm{C}$ after inoculation $\left(\mathrm{A}_{600} \sim \mathrm{nm}\right.$ : 0.05). Sporulation frequencies were determined as the ratio of chloroform-resistant colony forming units (CFUs) (number of colonies formed after treatment with $10 \%$ chloroform for 15 $\mathrm{min}$ ) to total CFUs (without chloroform treatment).

Spores were purified by removing remaining vegetative cells by incubating with lysozyme $(1.5 \mathrm{mg} / \mathrm{mL})$ for $1 \mathrm{~h}$ at $37^{\circ} \mathrm{C}$ 
followed by the addition of SDS (4\% final concentration) for another $30 \mathrm{~min}$. Spores were washed at least four times with water before storing at $4^{\circ} \mathrm{C}$.

\section{Flow cytometric analysis}

Cells were diluted 100 -fold in $0.2 \mu \mathrm{M}$ filtered minimal medium, and scatter and emission were directly measured on a Partec CyFlow Space flow cytometer (Partec) operating a $20 \mathrm{~mW}$ solidstate laser (488 nm) essentially as described (Veening et al. 2005). For each sample, at least 100,000 cells were analyzed. Data were captured and analyzed using FloMax software (Partec).

\section{Marker frequency analysis}

Origin/terminus ratios were essentially determined as described (Murray and Errington 2008). In brief, spore DNA was purified by first removing spore coat proteins followed by chloroform extraction (for further details, see the Supplemental Material). Power SYBR Green PCR Master Mix was used for PCR reactions (Applied Biosystems). Q-PCR was performed in a LightCycler 480 Instrument (Roche).

\section{Acknowledgments}

We thank Bill Burkholder, Alan Grossman, Richard Losick, Wiep Klaas Smits, Masa Suetsugu, Roger Tsien, and Thomas Wiegert for strains. J.W.V. was supported by a Ramsay Fellowship from the Royal Netherlands Academy of Arts and Sciences (KNAW) and by an Intra-European Marie-Curie Fellowship from the European Commission. H.M. was supported by post-doctoral fellowships from the European Molecular Biology Organization (EMBO) and the Human Frontier Science Program (HFSP). The overall work was supported by a grant from the Biotechnology and Biological Sciences Research Council to J.E.

\section{References}

Au N, Kuester-Schoeck E, Mandava V, Bothwell LE, Canny SP, Chachu K, Colavito SA, Fuller SN, Groban ES, Hensley LA, et al. 2005. Genetic composition of the Bacillus subtilis SOS system. J Bacteriol 187: 7655-7666.

Bischofs IB, Hug JA, Liu AW, Wolf DM, Arkin AP. 2009. Complexity in bacterial cell-cell communication: Quorum signal integration and subpopulation signaling in the Bacillus subtilis phosphorelay. Proc Natl Acad Sci 106: 64596464.

Breier AM, Grossman AD. 2009. Dynamic association of the replication initiator and transcription factor DnaA with the Bacillus subtilis chromosome during replication stress. I Bacteriol 191: 486-493.

Burbulys D, Trach KA, Hoch JA. 1991. Initiation of sporulation in $B$. subtilis is controlled by a multicomponent phosphorelay. Cell 64: 545-552.

Burkholder WF, Kurtser I, Grossman AD. 2001. Replication initiation proteins regulate a developmental checkpoint in Bacillus subtilis. Cell 104: 269-279.

Castilla-Llorente V, Munoz-Espin D, Villar L, Salas M, Meijer WJ. 2006. Spo0A, the key transcriptional regulator for entrance into sporulation, is an inhibitor of DNA replication. EMBO J 25: 3890-3899.

Collier J, Murray SR, Shapiro L. 2006. DnaA couples DNA replication and the expression of two cell cycle master regulators. $E M B O$ J 25: 346-356.

Cunningham KA, Burkholder WF. 2008. The histidine kinase inhibitor Sda binds near the site of autophosphorylation and may sterically hinder autophosphorylation and phosphotransfer to Spo0F. Mol Microbiol 71: 659-677.

Dawes IW, Kay D, Mandelstam J. 1971. Determining effect of growth medium on the shape and position of daughter chromosomes and on sporulation in Bacillus subtilis. Nature 230: 567-569.

Dunn G, Jeffs P, Mann NH, Torgersen DM, Young M. 1978. The relationship between DNA replication and the induction of sporulation in Bacillus subtilis. I Gen Microbiol 108: 189195.

Fujita M, Losick R. 2005. Evidence that entry into sporulation in Bacillus subtilis is governed by a gradual increase in the level and activity of the master regulator Spo0A. Genes \& Dev 19: 2236-2244.

Fujita M, Gonzalez-Pastor JE, Losick R. 2005. High- and lowthreshold genes in the Spo0A regulon of Bacillus subtilis. J Bacteriol 187: 1357-1368.

Goranov AI, Katz L, Breier AM, Burge CB, Grossman AD. 2005. A transcriptional response to replication status mediated by the conserved bacterial replication protein DnaA. Proc Nat1 Acad Sci 102: 12932-12937.

Harwood CR, Cutting SM. 1990. Molecular biological methods for Bacillus. John Wiley and Sons Ltd., Chichester, UK.

Hauser PM, Errington J. 1995. Characterization of cell cycle events during the onset of sporulation in Bacillus subtilis. J Bacteriol 177: 3923-3931.

Hilbert DW, Piggot PJ. 2004. Compartmentalization of gene expression during Bacillus subtilis spore formation. Microbiol Mol Biol Rev 68: 234-262.

Ishikawa S, Ogura Y, Yoshimura M, Okumura H, Cho E, Kawai Y, Kurokawa K, Oshima T, Ogasawara N. 2007. Distribution of stable DnaA-binding sites on the Bacillus subtilis genome detected using a modified ChIP-chip method. DNA Res 14: 155-168.

Katayama T. 2001. Feedback controls restrain the initiation of Escherichia coli chromosomal replication. Mol Microbiol 41: 9-17.

Kawai Y, Moriya S, Ogasawara N. 2003. Identification of a protein, YneA, responsible for cell division suppression during the SOS response in Bacillus subtilis. Mol Microbiol 47: 1113-1122.

Kelley WL. 2006. Lex marks the spot: The virulent side of SOS and a closer look at the LexA regulon. Mol Microbiol 62: 1228-1238.

Kornberg A, Baker TA. 1992. DNA replication, 2nd ed. Freeman, New York.

Lemon KP, Grossman AD. 1998. Localization of bacterial DNA polymerase: Evidence for a factory model of replication. Science 282: 1516-1519.

Lemon KP, Grossman AD. 2000. Movement of replicating DNA through a stationary replisome. Mol Cell 6: 1321-1330.

Mandelstam J, Higgs SA. 1974. Induction of sporulation during synchronized chromosome replication in Bacillus subtilis. I Bacteriol 120: 38-42.

Messer W, Weigel C. 1997. DnaA initiator: Also a transcription factor. Mol Microbiol 24: 1-6.

Molle V, Fujita M, Jensen ST, Eichenberger P, Gonzalez-Pastor JE, Liu JS, Losick R. 2003. The Spo0A regulon of Bacillus subtilis. Mol Microbiol 50: 1683-1701.

Mott ML, Berger JM. 2007. DNA replication initiation: Mechanisms and regulation in bacteria. Nat Rev Microbiol 5: 343-354.

Murray AW. 2004. Recycling the cell cycle: Cyclins revisited. Cell 116: 221-234.

Murray H, Errington J. 2008. Dynamic control of the DNA replication initiation protein DnaA by Soj/ParA. Cell 135: 74-84. 
Perego M, Spiegelman GB, Hoch JA. 1988. Structure of the gene for the transition state regulator, $a b r B$ : Regulator synthesis is controlled by the spoOA sporulation gene in Bacillus subtilis. Mol Microbiol 2: 689-699.

Rahn-Lee L, Gorbatyuk B, Skovgaard O, Losick R. 2009. The Conserved Sporulation Protein YneE inhibits DNA replication in Bacillus subtilis. J Bacteriol 191: 3736-3739.

Rowland SL, Burkholder WF, Cunningham KA, Maciejewski MW, Grossman AD, King GF. 2004. Structure and mechanism of action of Sda, an inhibitor of the histidine kinases that regulate initiation of sporulation in Bacillus subtilis. Mol Cell 13: 689-701.

Ruvolo MV, Mach KE, Burkholder WF. 2006. Proteolysis of the replication checkpoint protein Sda is necessary for the efficient initiation of sporulation after transient replication stress in Bacillus subtilis. Mol Microbiol 60: 1490-1508.

Schaeffer P, Millet J, Aubert JP. 1965. Catabolic repression of bacterial sporulation. Proc Natl Acad Sci 54: 704-711.

Shapiro L, Losick R. 2000. Dynamic spatial regulation in the bacterial cell. Cell 100: 89-98.

Soufo CD, Soufo HJ, Noirot-Gros MF, Steindorf A, Noirot P, Graumann PL. 2008. Cell-cycle-dependent spatial sequestration of the DnaA replication initiator protein in Bacillus subtilis. Dev Cell 15: 935-941.

Spizizen J. 1958. Transformation of biochemically deficient strains of Bacillus subtilis by deoxyribonucleate. Proc Natl Acad Sci 44: 1072-1078.

Sterlini JM, Mandelstam J. 1969. Commitment to sporulation in Bacillus subtilis and its relationship to development of actinomycin resistance. Biochem J 113: 29-37.

Veening JW, Hamoen LW, Kuipers OP. 2005. Phosphatases modulate the bistable sporulation gene expression pattern in Bacillus subtilis. Mol Microbiol 56: 1481-1494.

Veening JW, Stewart EJ, Berngruber TW, Taddei F, Kuipers OP, Hamoen LW. 2008. Bet-hedging and epigenetic inheritance in bacterial cell development. Proc Natl Acad Sci 105: 43934398.

Walworth NC. 2000. Cell-cycle checkpoint kinases: Checking in on the cell cycle. Curr Opin Cell Biol 12: 697-704.

Wang JD, Sanders GM, Grossman AD. 2007. Nutritional control of elongation of DNA replication by (p)ppGpp. Cell 128: 865875.

Whitten AE, Jacques DA, Hammouda B, Hanley T, King GF, Guss JM, Trewhella J, Langley DB. 2007. The structure of the KinA-Sda complex suggests an allosteric mechanism of histidine kinase inhibition. J Mol Biol 368: 407-420. 


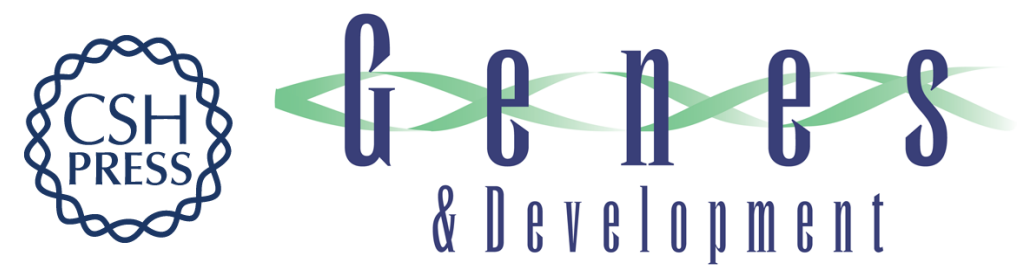

\section{A mechanism for cell cycle regulation of sporulation initiation in Bacillus subtilis}

Jan-Willem Veening, Heath Murray and Jeff Errington

Genes Dev. 2009, 23:

Access the most recent version at doi:10.1101/gad.528209

Supplemental http://genesdev.cshlp.org/content/suppl/2009/07/23/23.16.1959.DC1
Material

References This article cites 41 articles, 15 of which can be accessed free at:

http://genesdev.cshlp.org/content/23/16/1959.full.html\#ref-list-1

License

Email Alerting

Receive free email alerts when new articles cite this article - sign up in the box at the top

Service

right corner of the article or click here.

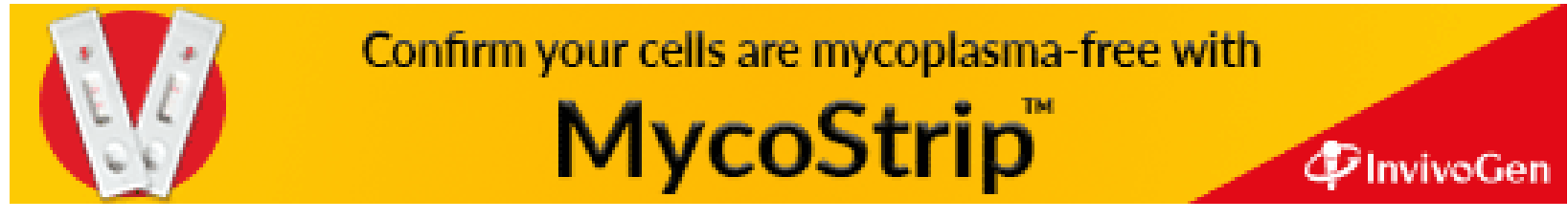

